\title{
APPLICATION OF THE ELECTRICAL RESISTIVITY METHOD TO IDENTIFY KARST FEATURES: GEOTECHNICAL AND/OR GEOENVIRONMENTAL IMPLICATIONS FOR HYDROCARBON EXPLORATION AREAS
}

\author{
Lucas Miguel Gomes Nunes ${ }^{1}$, Carlos César Nascimento da Silva ${ }^{1}$ \\ and Leandson Roberto Fernandes de Lucena²
}

\begin{abstract}
Areas with geological substrate composed of carbonate rocks, such as some areas of hydrocarbons exploration and production, occasionally may be related to cases of subsidence of the surface, sometimes caused by the instability of the areas associated with zones of dissolution and its voids, which commonly evolve from systems of pre-existing fractures. The physical infrastructure of these areas (buildings, oil storage tanks and waste materials, and others) can be compromised, affecting, in turn, the integrity of the geological substrate from an environmental point of view. This context includes the epigenetic karst, associated with the percolation of rainwater, focus of this work. Thus, the use of geophysical methods (notably the resistivity) allows to analyze satisfactorily, in terms of resolution and depth of investigation, the carbonate substrate and their areas of dissolution. Therefore, this research shows initially a modelling phase of several hypothetical karst systems, for the purpose of compare the different responses of the arrays used (Schlumberger, Dipole-Dipole and Wenner), followed by a qualitative analysis of real data collected in the field, which were used as a basis for defining the values of geoelectric models, from an interactive analysis. In this phase of forward modeling, synthetic geoelectrical models were generated in order to simulate an approximate geology characterized by karstic features and its geoelectric response. The inversion process aimed at validating the geophysical responses obtained from the initial models and, thus, eliminate any distortions observed in the pseudo-sections of apparent resistivity, adjusting the values of the electrical resistivity to values near the initial model proposed. Finally, the data initially modeled were corroborated by the real data.
\end{abstract}

Keywords: karst, geoelectrical, modeling, environment, geotechnics.

RESUMO. Regiões que apresentam substrato geológico composto por rochas carbonáticas, a exemplo de algumas áreas de exploração e produção de hidrocarbonetos, podem estar associadas a casos de abatimento da superfície do terreno, provocados ocasionalmente pela instabilidade das áreas relacionadas a zonas de dissolução e seus vazios, os quais, por sua vez, comumente evoluem a partir de sistemas de fraturas pré-existentes. A infraestrutura física destas áreas (edificações, tanques de armazenamento de petróleo e seus resíduos, entre outras) pode ser comprometida, afetando a integridade do substrato geológico do ponto de vista ambiental. Este contexto engloba o carste epigenético, associado à percolação de águas meteóricas, foco do presente trabalho. Deste modo, o uso de métodos geofísicos (notadamente a eletrorresistividade) permite analisar de maneira satisfatória, quanto aos aspectos de resolução e profundidade de investigação, o substrato carbonático e as respectivas zonas de dissolução. Para tanto, este trabalho de pesquisa trata inicialmente de uma fase de modelagem de diversos sistemas cársticos hipotéticos, de modo a comparar as diferentes respostas dos arranjos utilizados (Schlumberger, Dipolo-Dipolo e Wenner), seguida da análise qualitativa de dados reais coletados em campo, os quais foram utilizados como base para a definição dos valores dos modelos geoelétricos, a partir de uma análise interativa. Nesta etapa de modelagem direta foram gerados modelos geoelétricos sintéticos, a fim de simular de forma aproximada uma geologia caracterizada por feições cársticas e sua resposta geoelétrica. 0 processo de inversão nos dados obtidos pela etapa da modelagem buscou validar as respostas geofísicas obtidas a partir dos modelos iniciais e assim eliminar as eventuais distorções observadas nas pseudo-seções de resistividade aparente, ajustando os valores de resistividade elétrica a valores próximos do modelo inicial proposto. Por fim, os dados modelados inicialmente foram corroborados pelos dados reais.

Palavras-chave: carste, geoelétrico, modelagem, meio ambiente, geotecnia.

\footnotetext{
${ }^{1}$ Universidade Federal do Rio Grande do Norte-UFRN, Departamento de Geofísica, Campus Universitário, Lagoa Nova, 59078-700 Natal, RN, Brazil. Phone: +55(84) 3342-2237; Fax: +55(84) 3342-2503 - E-mail: lucas_sns@hotmail.com; carloscesar@geofisica.ufrn.br

2 Universidade Federal do Rio Grande do Norte-UFRN, Pós-Graduação em Geodinâmica e Geofísica-PPGG, Campus Universitário, Lagoa Nova, 59078-970 Natal, RN, Brazil - E-mail: leandson@geofisica.ufrn.br
} 


\section{INTRODUCTION}

Hydrocarbon exploration is commonly performed in remote areas, in many cases without the real knowledge of the shallow geological substrate. Additonally, the infrastructure of the oil industry in these areas is usually related to buildings of different sizes, the constant traffic of small, medium and large vehicles, as well as products and waste resulting from the exploration activity over tanks and contention dikes. Thus, knowledge of the geological subtrate is essential from the safety point of view of what is surface (infrastructure and passersby) as well as maintaining the physical integrity of the fluid storage locations. Depending on the nature of the product resulting from oil exploration, typically oil or water produced with high concentration of hydrocarbon, the breaking of any fluid containment element can cause serious damage to the environment. The lack of knowledge of the nature of the substrate, especially in regions of carbonate rocks due to the complex nature of the percolation fluids routes, potentially increases the degree of remediation of affected areas.

Regions with geological substrate composed of carbonate rocks, sometimes can be related to cases of subsidence of the surface, occasionally caused by the instability of the areas associated with zones of dissolution and its voids. In turn, these areas of dissolution, according to Silva (2008), in their majority, are a reflection of the evolution of networks of fracturing and pre-existing discontinuities in the rock as a result of the action of meteoric waters at environment, creating the so-called karst system epigenetic (Fig. 1).

Considering this, it's extremely important to identify these discontinuities and set out (at least qualitatively) the areas that present the greatest geotechnical risk to existing buildings on the surface, or even to passersby in the area. However, direct contact with carbonate rock is, often hampered by the presence of a weathered soil cover, mainly in tropical environments where the weathering action and climatic seasonality provide the genesis of thick alteration mantles.

In this context, the use of geophysical methods (notably the resistivity) may allow to analyze satisfactorily in terms of resolution and depth of investigation of the carbonate substrate and its zones of dissolution (fractures) and precipitation (cavities).

There is controversy about the use of geoelectric techniques, especially electrical resistivity, for imaging karstic regions due to the geological and structural complexity, which is, from a geophysical point of view, mainly characterized by lateral and vertical variations of the physical property measurement, the apparent resistivity. Konstantinos et al. (2011) say that conventional geoelectric techniques are not viable in such areas. However, these authors give credit to the use of 2D and 3D models, mainly relating the geophysical information to the lithological nature of the carbonate or filling the cavity in the subsurface (usually air or clayey material often saturated with water). Proving this, ElQady et al. (2005) satisfactorily imaged the bedrock of southeastern Cairo, Egypt, with geotechnical purposes, to identify system of caves and sinkholes in urban areas. In this case, the karstic system of area is linked by subvertical linear fractures. Gautam et al. (2000) identified resistivity anomalies in geoelectric techniques associated with areas of caves and other karstic features. Loke et al. (2013) realized a large and detailed analysis on the electrical imaging methods emphasizing technological advances in the last two decades concerning the acquisition of data and inversion techniques. In this case, the use of different electrode arrangements allows, among others, parameterize its acquisition over the nature, form, size and general characteristics of the target prospect.

Delgado-Rodríguez et al. (2006) applied of geoelectric methods to image contaminated sites by hydrocarbons from the rupture of pipes and their relationship with the surrounding aquifer. Depending on the residence time in the substrate (more than 30 years in the case) and bacterial action in their own hydrocarbon, the contamination was related to conductive anomalies. Such anomalies related to substrate contamination were also identified by Shevnin et al. (2003) and Shevnin et al. (2005). The differential of this work was to identify low resistivity anomalies in a medium with presence of clay. Atekwana et al. (2000) performed the assessment of use and results of contaminated sites by hydrocarbons through integrated geophysical techniques, among them the $2 \mathrm{D}$ resistivity. Despite the geoelectric technique does not allow, alone, solve the contaminated area, the presence of conductive anomalies and their relationship with the high resistivity regions made it possible to identify and suggest a simple and intuitive model for the area.

In order to evaluate the effectiveness of the resistivity method to identify karstic features, synthetic geoelectric models were generated for the purpose of simulating an actual field situations in an approximate way, within a geological context of carbonate rocks. Real data obtained in the field were employed and used as basis for defining the values adopted in geoelectrical models and could corroborate the modeled data.

This work aimed to evaluate the efficacy and the degree of reliability of the electrical resistivity geophysical method in the imaging of epigenetic karst features, from integrated correlation between geophysical data and geological information available, consolidating the information about the geotechnical aspects and the environment. 


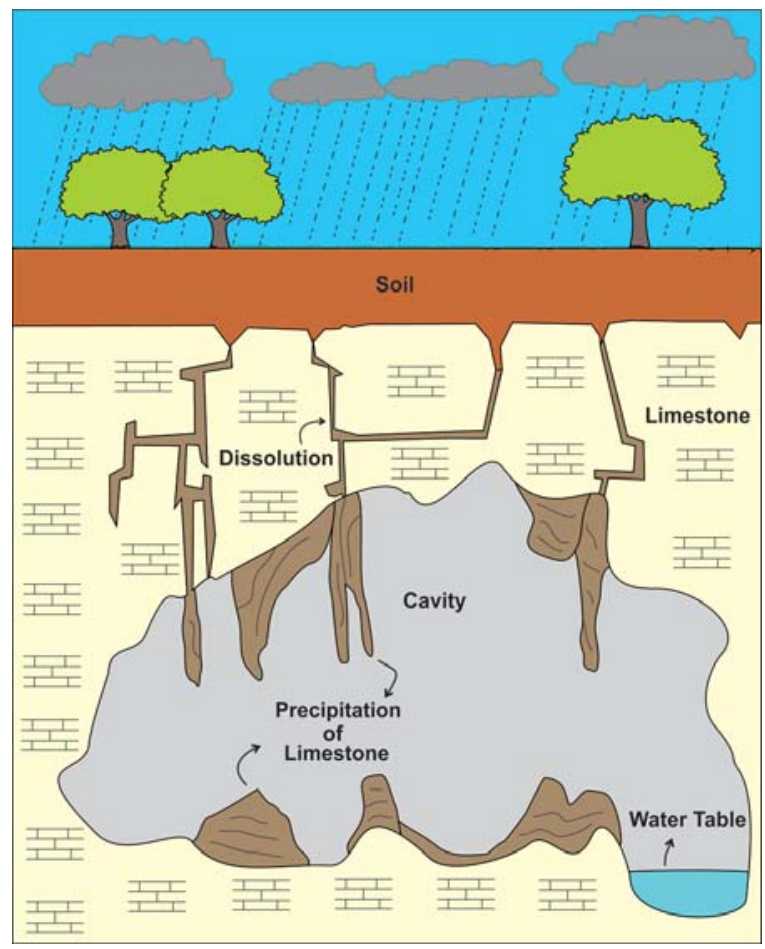

Figure 1 - General aspects of karst features and its interaction with the surface.

\section{GEOELECTRICAL METHOD}

Currently, one of the methods used to identify karst features is the resistivity method, which is based on the determination of the apparent resistivity of the substrate from measurements of the electric potential difference between two points on the ground, associated with the flow of an electrical stream (Ward, 1990). The method consists of the application of an artificial electrical current into the ground through two current electrodes ( $A$ and $B$ ) located on the surface of the soil (Fig. 2), in an attempt to measure the electrical potential generated in the potential electrodes ( $\mathrm{M}$ and $\mathrm{N}$ ) near to the current flow, allowing to determine the electrical resistivity in the subsurface (Orellana, 1972).

Assuming Ohm's Law (Eq. 1), which define that the product of the electrical resistance $\mathbf{R}$ and the electric current $i$ is proportional to the electric potential $V$, it's possible to obtain the equation of the resistivity (Eq. 2), where $k$ is a factor geometric and $\Delta V$ is the potential difference measured.

$$
\begin{aligned}
& V=\mathbf{R} \cdot i \\
& \rho=k\left(\frac{\Delta V}{i}\right)
\end{aligned}
$$

\section{GEOELECTRICAL MODELING}

The geoelectric modeling aims to generate synthetic models to simulate a known geological environment and from mathemati- cal calculations, to obtain the associated physical responses (in this case, the resistivity parameter). Thus, it is possible to represent actual field situations considering surveys with different arrangements and spacing of electrodes. Therefore, the forward modeling is considered an extremely useful tool in the evaluation of the most appropriate arrangements for different surveys and geological situations and comparing these synthetic results with those obtained in the field. For the stage of forward modeling, it was used the geoelectric modeling software RES2DMOD (Loke, 2002). The program calculates pseudo-sections of apparent resistivity, simulating the use of the technique of Electrical Imaging (IE) two-dimensional and certain arrays defined by the user. The data obtained by modeling went through an inversion process, using the software RES2DINV (Geotomo, 2007), in order to try to reduce the difference between the modeled resistivity values and the calculated ones, as well as evaluating the effectiveness and reliability of the processes.

The analysis of several synthetic models analogous to the geological context of regions with carbonate rocks was carried out, initially considering models with a simpler geology to more complex models with the purpose of simulating, in an approximate way, to a geology characterized by karst features. Different arrangements of electrodes (Schlumberger, Wenner and DipoleDipole) were used, which had its advantages and disadvantages with regard to resolution and depth of investigation, yielding different answers. Each model had modifications that simulated vertical and horizontal discontinuities in the limestone with different resistivity values, and different levels of water saturation and degree of connectivity.

In all models were used 60 electrodes with spacing between them equal to $5 \mathrm{~m}$. The number of electrodes was maintained in all arrangements aiming geophysical responses related only to the heterogeneity of the geological environment, without being influenced by a possible variation of the parameter acquisition. The resistivity values used in the model were defined taking as a basis the real data obtained in field and most widely used and observed values in different bibliographic materials, such as Fernandes (1984) and Loke (2004). The model simulated a survey along a profile $295 \mathrm{~m}$, investigating 16 different depth levels, associated with the investigation capacity of each array used.

\section{SYNTHETIC RESULTS}

\section{Forward Modeling}

\section{1st Modeling (Resistive Simple Model)}

The first model sought to simulate a simple geology with the cavity filled with air, considering the following template (Fig. 3). 


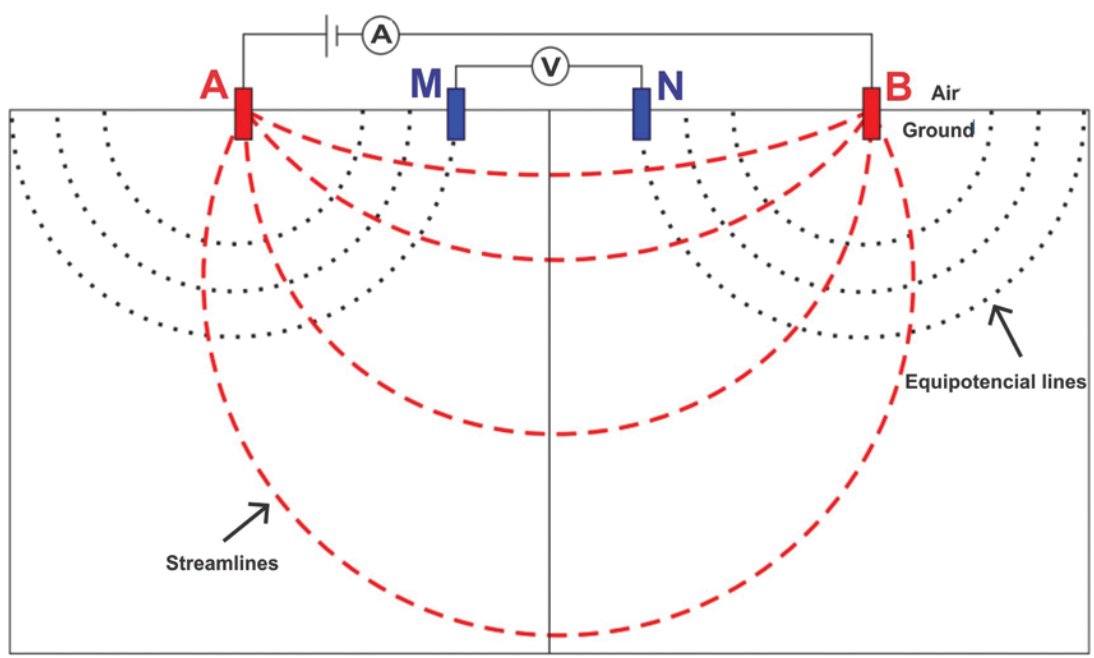

Figure 2 - Illustration of the behavior of the streamlines and equipotential during an investigation of vertical resistivity, using two current electrodes (red) and two potential electrodes (blue).

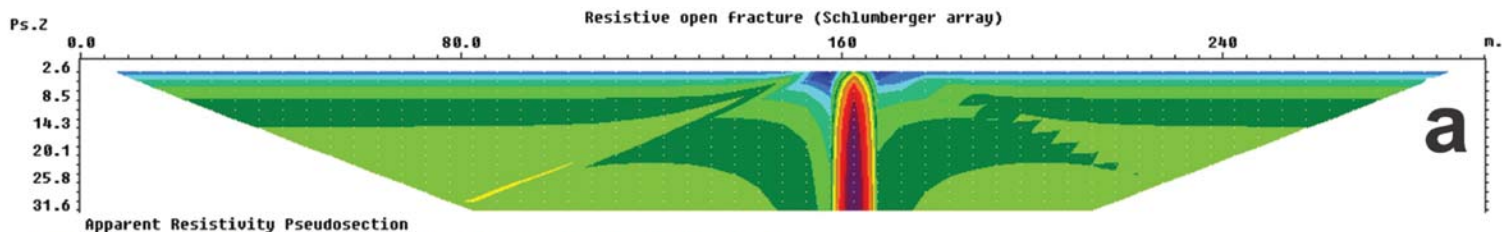

\section{$\square_{364}^{\text {Apparent Resistivity Pseudosection }} \square_{578} \square \square \square \square$}

4080 300

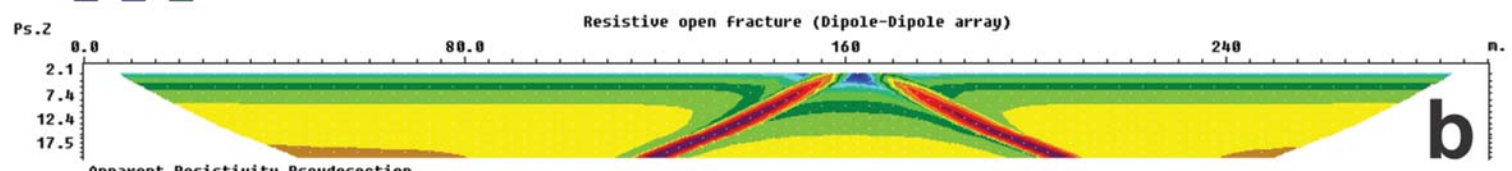

\section{Apparent Resistivity Pseudosection}

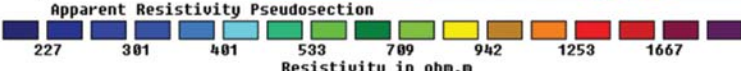

4000 300
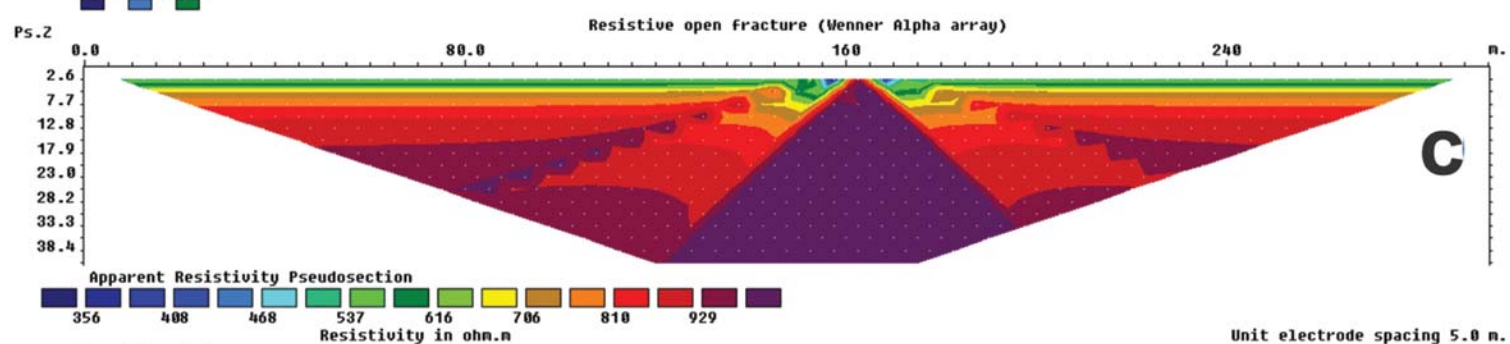

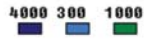

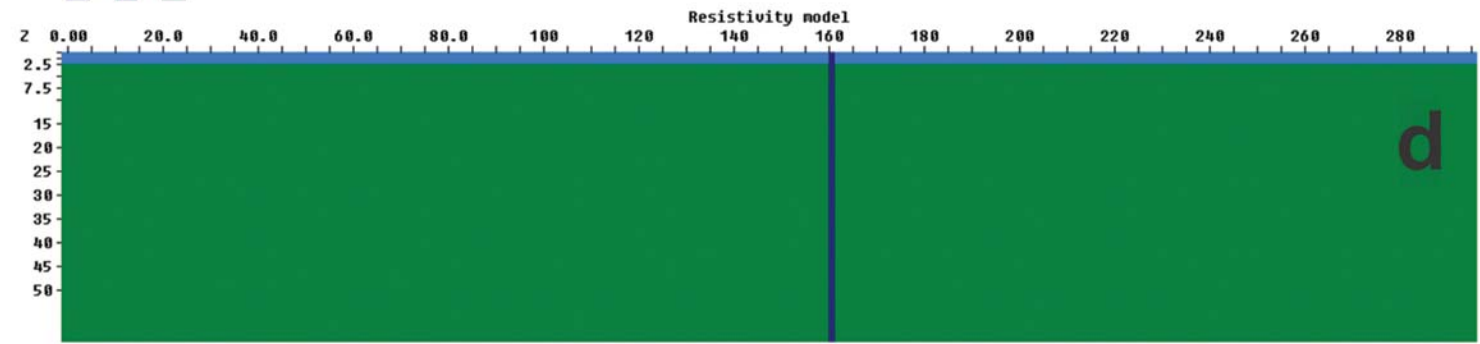

Figure 3 - Geoelectric responses of model arrays: (a) Schlumberger (SLB), (b) Dipole-Dipole (DD), (c) Wenner (WN) and (d) synthetic geological model (Mod) with vertical fractures with air (the green color is limestone, light blue is the sedimentary cover and dark blue is the fracture). 


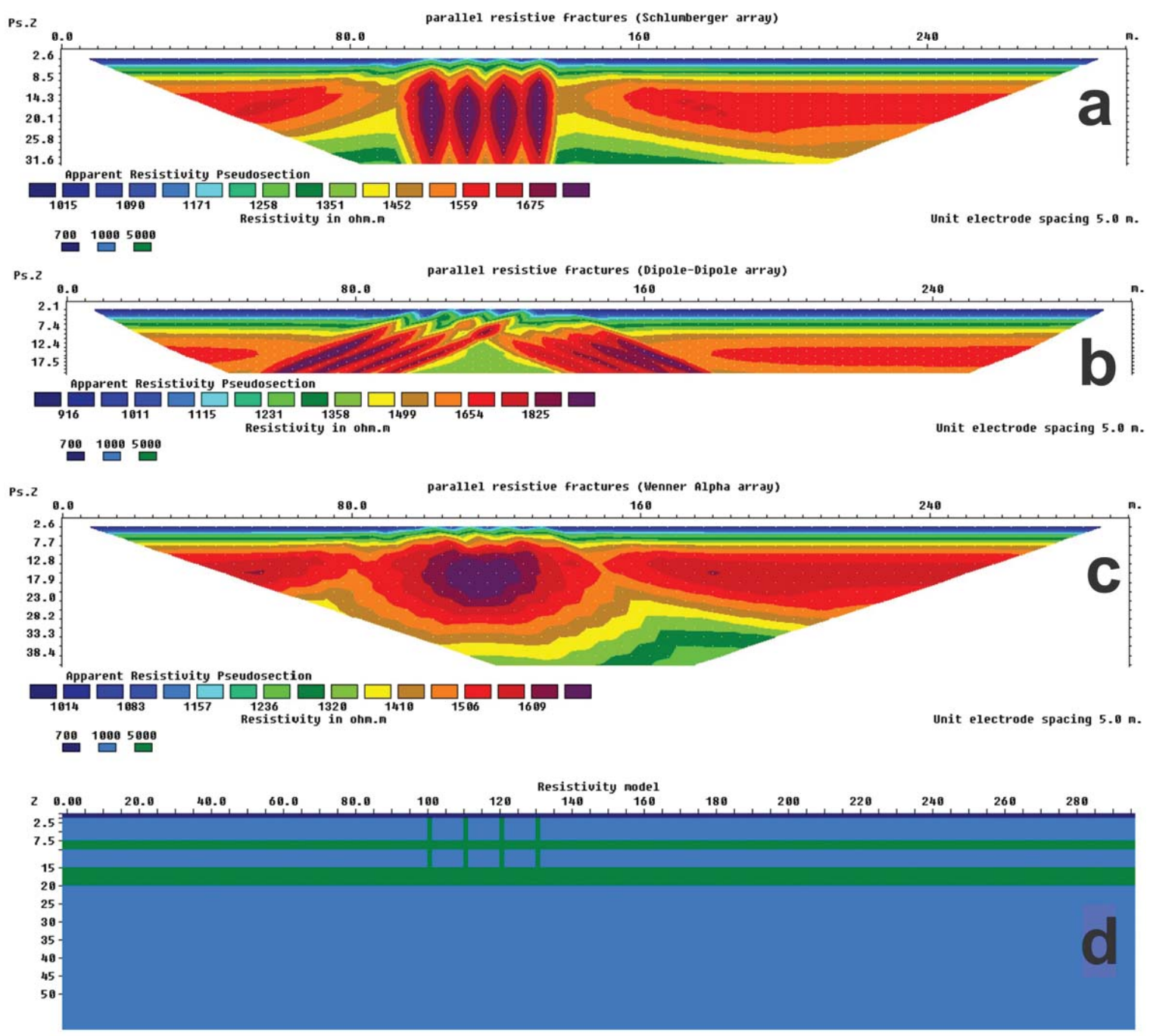

Figure 4 - Geoelectric responses of model arrays: (a) Schlumberger (SLB), (b) Dipole-Dipole (DD), (c) Wenner (WN) and (d) synthetic geological model (Mod) with plane-horizontal layers (light blue color is limestone and dark blue is the sedimentary cover), besides horizontal and vertical cavities with high resistivity (green).

The plane-horizontal upper layer represented a sedimentary cover with resistivity $300 \Omega . \mathrm{m}$ and $2.5 \mathrm{~m}$ thick, while the lower layer was associated with a carbonate rock (limestone), resistivity $1000 \Omega$.m and the vertical cavity was associated with a fracture not saturated by water, filled with air with resistivity $4000 \Omega . m$ (width of $1.25 \mathrm{~m}$ ), discordantly cutting the limestone.

\section{2nd Modeling (Resistive Complex Model)}

In the second model, the results obtained represent more complex geological models (Fig. 4). Among plane-horizontal layers, the upper layer simulated a surface layer of sediments $(700 \Omega . \mathrm{m})$ with a thickness of $1.25 \mathrm{~m}$ and the lower layer represented limestone $(1000 \Omega$.m). The bedding of the carbonate rock was simu-

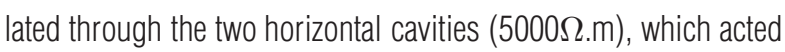
as zones of dissolution and high resistivity. The upper horizontal cavity is at a depth of $7.5 \mathrm{~m}$ and a thickness of $2.5 \mathrm{~m}$, while the top of the lower horizontal cavity is at a depth of $15 \mathrm{~m}$ and a thickness of $5 \mathrm{~m}$. Four vertical fractures (1.25 $\mathrm{m}$ wide each) were simulated, with $10 \mathrm{~m}$ apart from each other, located $1.25 \mathrm{~m}$ below the surface layer, connecting the two horizontal subsurface cavities. In this case, the parallel vertical fractures showed resistive anomalies, seeing there was no sediment or water saturated.

\section{3rd Modeling (Condutive Complex Model)}

The third model proposed is similar to the previous model, differing only in the resistivity of the lower cavities, affected by 


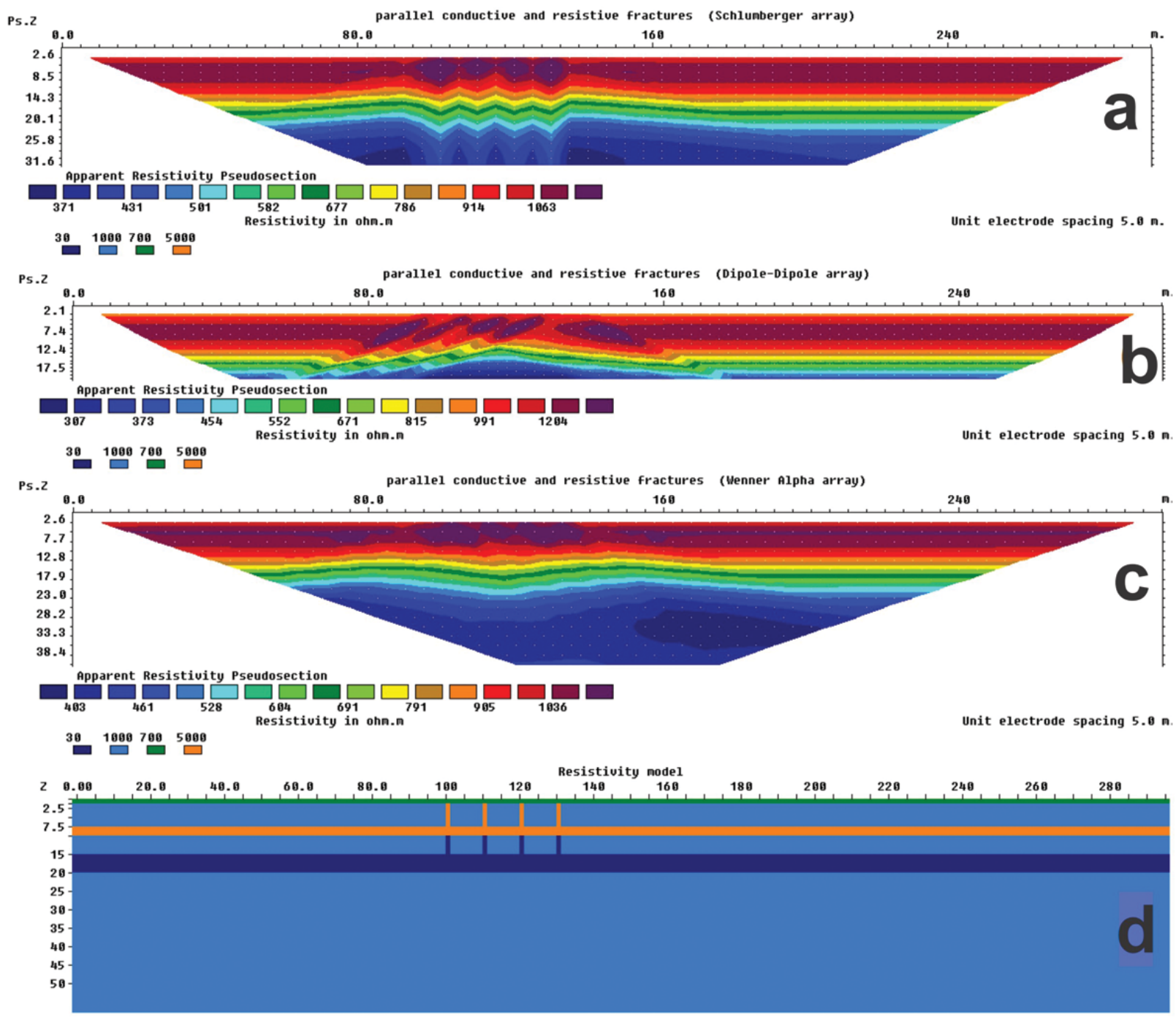

Figure 5 - Geoelectric responses of model arrays: (a) Schlumberger (SLB), (b) Dipole-Dipole (DD), (c) Wenner (WN) and (d) synthetic geological model (Mod) with plane-horizontal layers, besides horizontal and vertical cavities (light blue color is limestone, a sedimentary cover is green, dark blue is saturated cavities in water and orange is the cavities saturated with air). It features conductive geoelectrical behavior in the lower layers (simulating water table to $10 \mathrm{~m}$ depth) and a resistive behavior in the shallower layers (above the water table).

groundwater level (Fig. 5). The horizontal and vertical cavities simulated lower zones of saturated dissolution in water (water

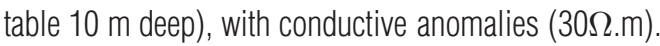

\section{INVERSION}

After the step of forward modeling, the data passed through an inversion process. The program used was RES2DINV, which uses an inversion routine based on the smoothness constrained leastsquare method (Degroot-Hedlin \& Constable, 1990).

In the method of least squares inversion, two norms can be applied to constraint: the optimization method with smoothness constrained that minimizes the L2 norm ("Smoothing Inversion
Method") and the optimization method with smoothness constrained that minimizes the L1 norm ("Robust Inversion") (Claerbout et al., 1973).

In the inversion of the data, two smoothness parameters were tested: the damping factor and the flatness filter. The damping factor tries to smooth the resistivity variations, may produce more unfocused and smooth images (if used lower values) or more focused and more distortions in the resistivity values (if used a damping factor higher-value) (Sasaki, 1992). The value of the damping factor is related to the noise level of the data, being used higher values (about 0.25 to the initial factor and 0.10 to the minimum damping factor) for more noisy data being used. The other 

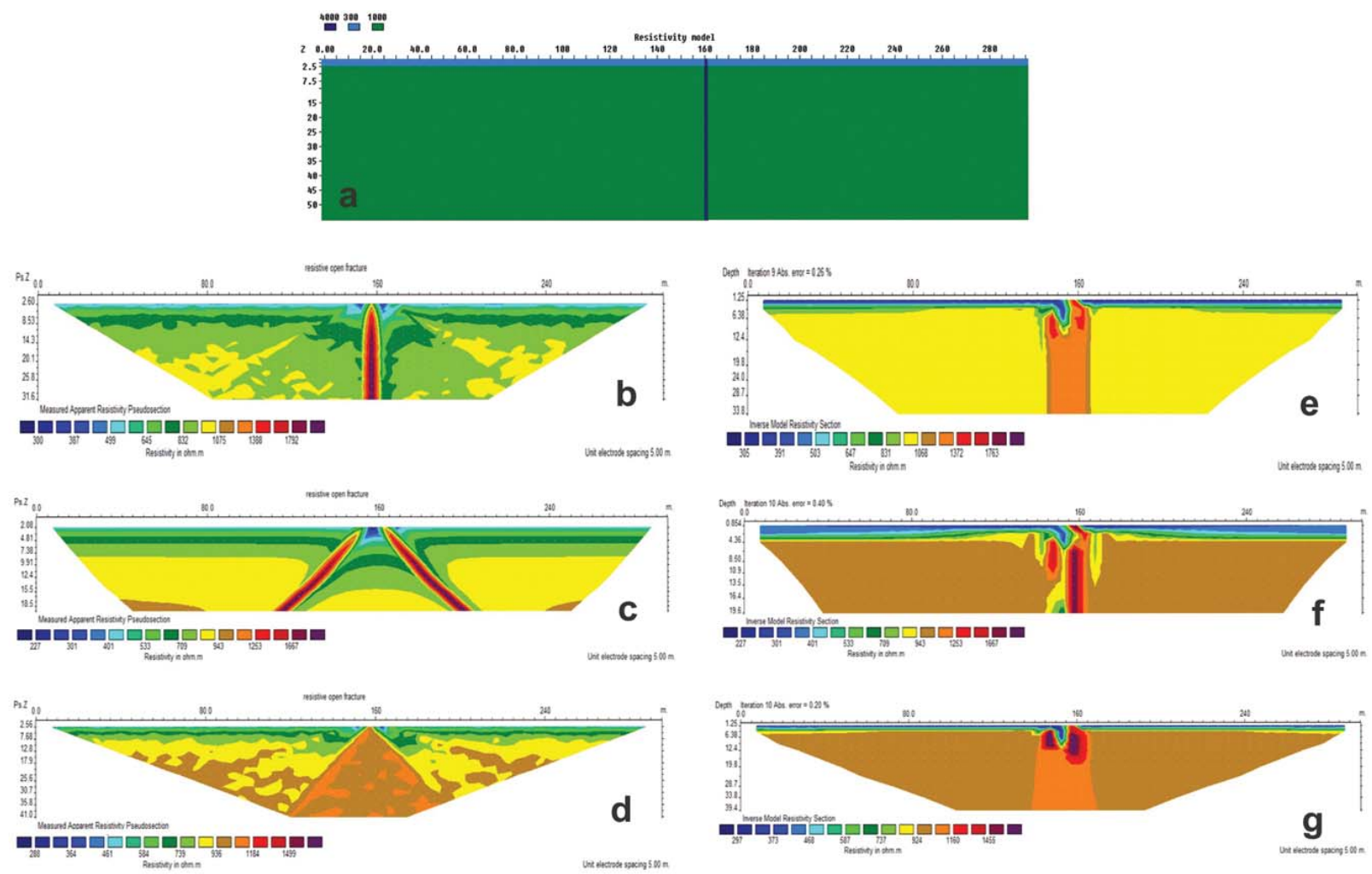

Figure 6 - Geological model proposed in first modeling (a); Pseudo-section of apparent resistivity according to Schlumberger (b), Dipole-Dipole (c) and Wenner (d) array; Inversion model resistivity section according to Schlumberger (e), Dipole-Dipole (f) and Wenner ( $\mathrm{g}$ ) array. Robust inversion with flatness filter was applied equal to 2.0 (emphasazing vertical anomalies).

parameter adjusted and that achieved satisfactory results during the phase inversion was the flattening filter. The RES2DINV software allows to adjust the vertical/horizontal ratio of flatness filter (where $f_{x}$ is the horizontal flatness filter and $f_{z}$ is the vertical flatness filter), being able to emphasize, depending on the filter, vertical or horizontal structures. For the case of pseudosections with anomalous resistivity more elongated vertically, assigning greater weight to the ratio for the flatness filter (for example 2.0), the process will generate models with more elongated vertically responses, emphasizing the vertical anomalies. Otherwise, for resistivity anomalies flatter, may be applied a weight less than 1.0 (for example 0.5), thus emphasizing the horizontal resistivity anomalies.

In order to facilitate comparison of results, were selected the responses of Schlumberger, Dipole-Dipole and Wenner arrays, from each of the models shown in the figures below. The first column (left) presents the pseudo-sections of apparent resistivity and the second column (right) presents sections of electrical resistivity, from each arrangement according to the same model resulting from the inversion process. The parameterizations used in each inversion process are described in the legends of Figures 6, 7 and 8 , and the results are featured below.

\section{APPLICATION ON REAL DATA}

In this section will be showed the real data (electrical section) that were used as basis for defining the values applied in the geoelectric models as well as it were used to corroborate the modeled data. The real data was collected in December 2012, into an oil exploration area in the Potiguar Basin, northeast of Brazil, near the Leste de Poço Xavier (LPX) Field, in Felipe Guerra County, in the Rio Grande do Norte State (Fig. 9).

In this phase, it was used IPI2Win software, version 2.1 (Bobachev et al., 2000). The program is used for data interpretation 1D Vertical Electrical Soundings (VES) along a profile. Real data was acquired over a secondary road, adjacent to the outcropping limestone (Fig. 10), in which were performed 10 VES (using a single channel equipment - Terrameter SAS 300C), with spacing of $20 \mathrm{~m}$ between, them using the Schlumberger array. Thus, resistivity sections and pseudo-sections were generated. 

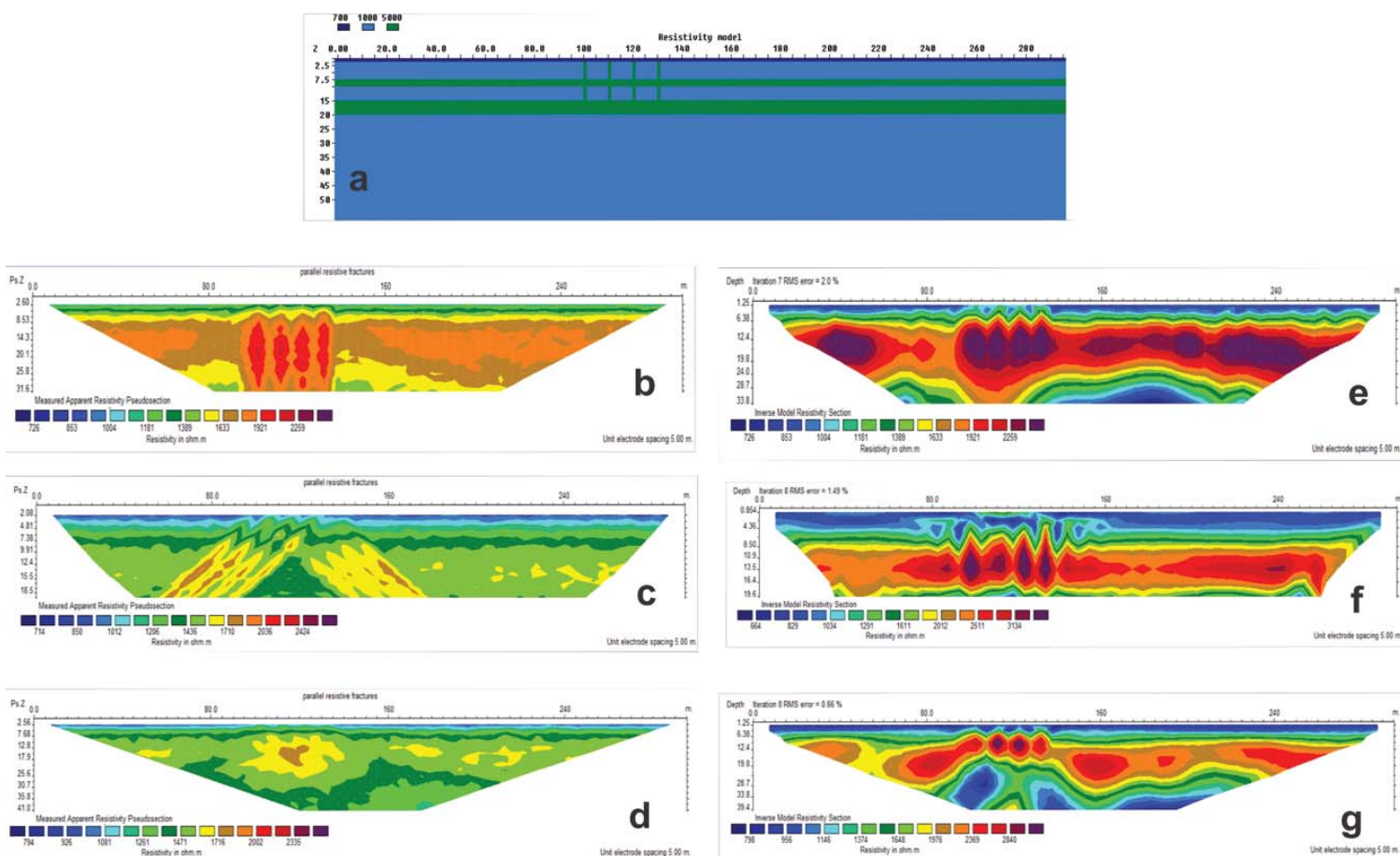

Figure 7 - Geological model proposed in second modeling (a); Pseudo-section of apparent resistivity according to Schlumberger (b), Dipole-Dipole (c) and Wenner (d) array; Inversion model resistivity section according to Schlumberger (e), Dipole-Dipole (f) and Wenner (g) array. Smoothing inversion was applied, with flatness filter equal to 2.0 (emphasizing vertical anomalies).
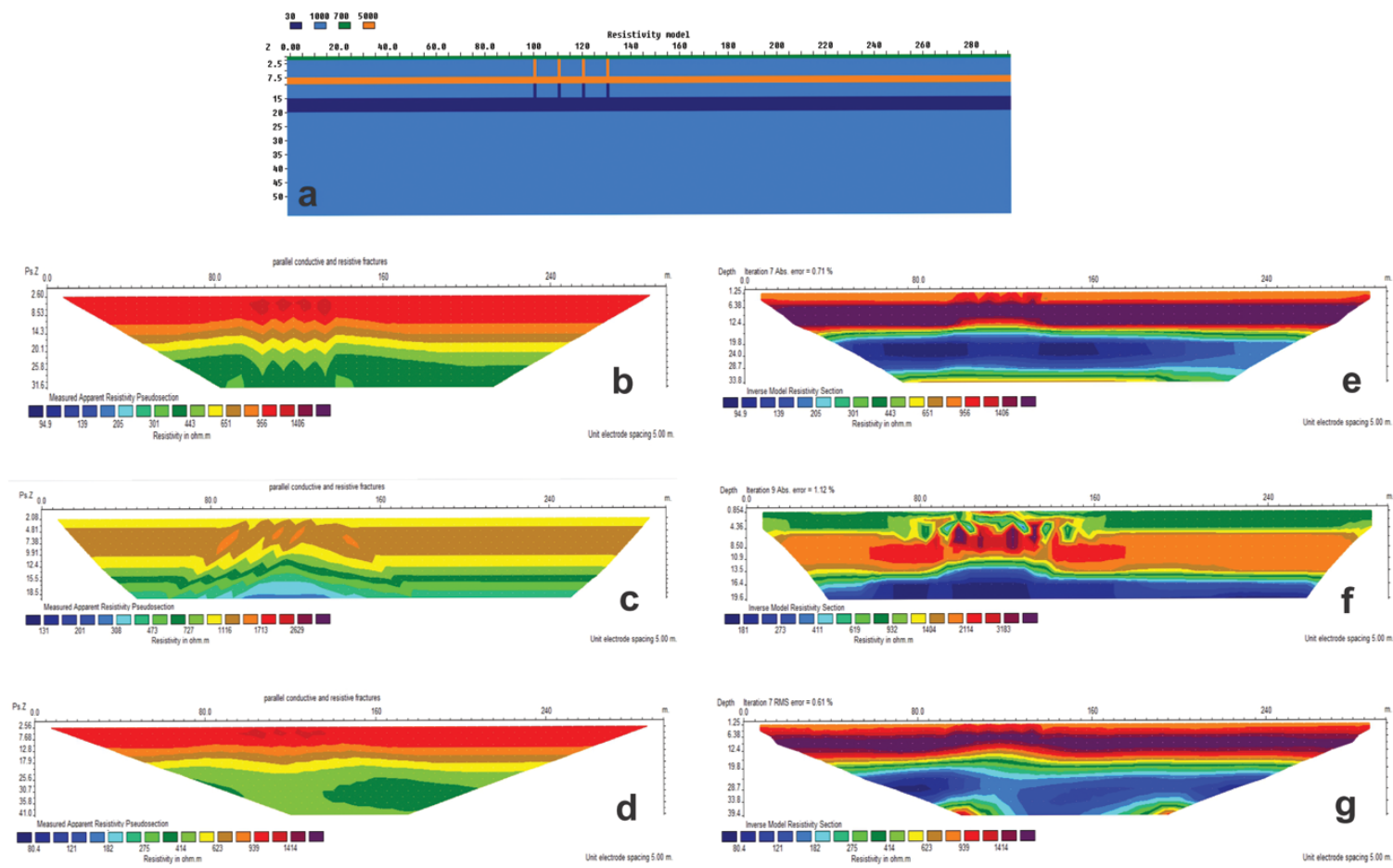

Figure 8 - Geological model proposed in third modeling (a); Pseudo-section of apparent resistivity according to Schlumberger (b), Dipole-Dipole (c) and Wenner (d) array; Inversion model resistivity section according to (e) Schlumberger (robust inversion with flatness filter was applied equal to 0.5, highlighting horizontal anomalies); (f) Dipole-Dipole (smoothing inversion was applied, with flatness filter equal to 2.0, emphasizing vertical anomalies); (g) Wenner array (smoothing inversion was applied, with flatness filter equal to 2.0, emphasizing vertical anomalies). 


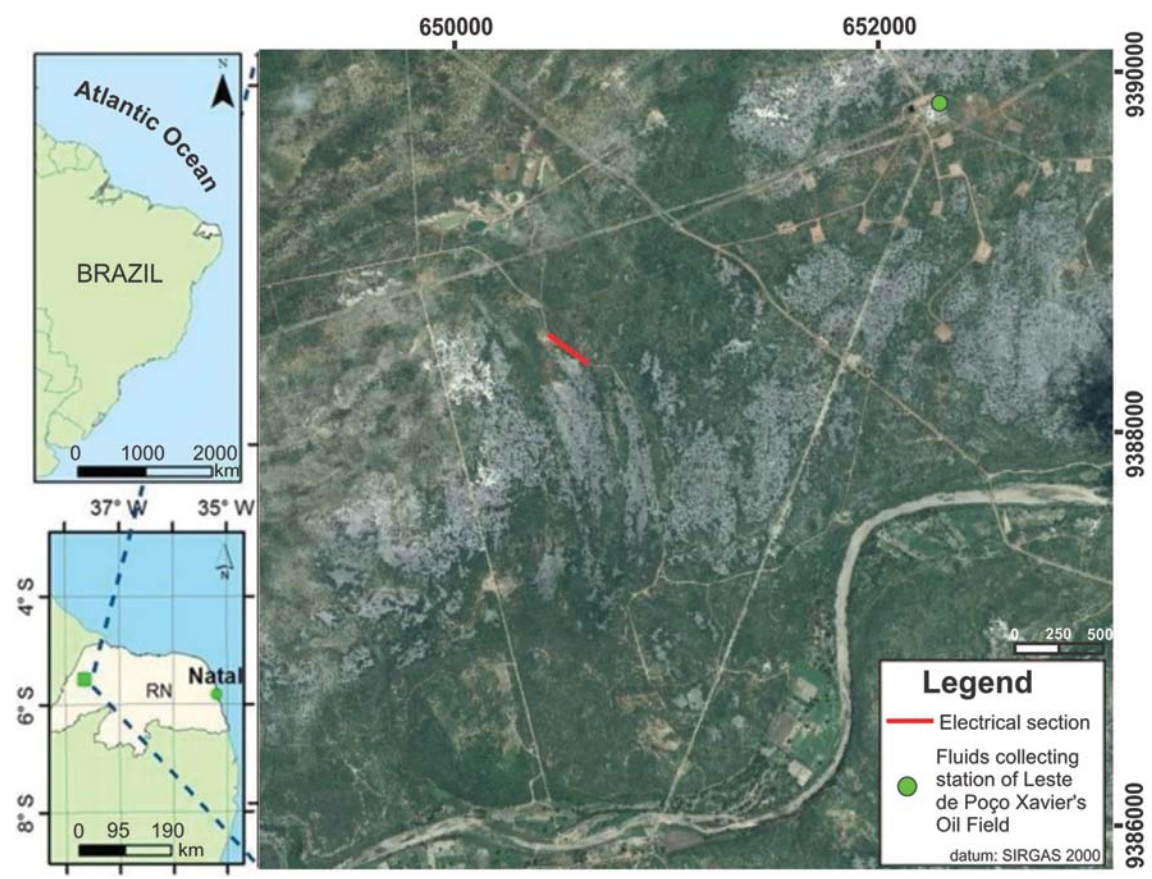

Figure 9 - Geographic location map of the electrical section from satellite images (highlighted by the red line).

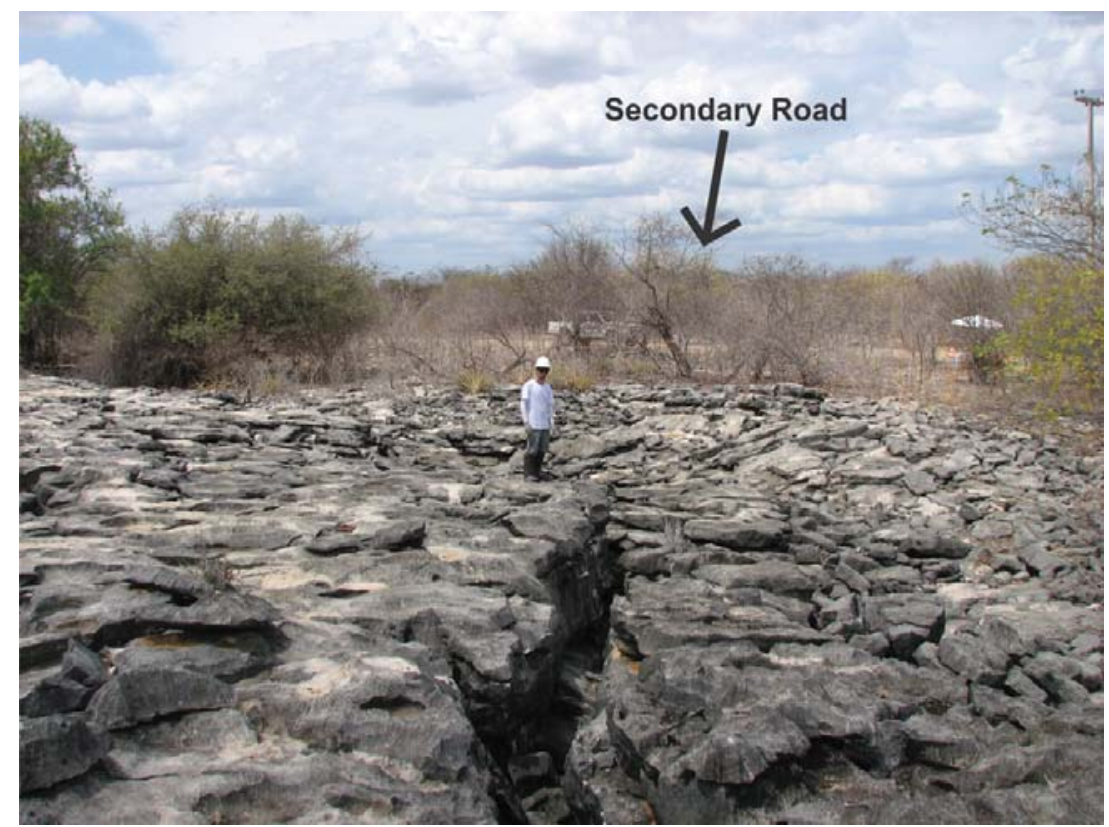

Figure 10 - Limestone outcrops and features of subsidence on the rigth adjacent to secondary road, where the data of VES's were acquired in the county of Felipe Guerra-RN. See location on Figure 9.

For data acquisition of VES were used $\mathrm{AB} / 2$ equal to 2, 5, 10, 20, 50, $100 \mathrm{~m}$. The resistivity curves of VES04, VES07 and VES08 and their geoelectric model can be observed in Figures 11, 12 and 13 , respectively. In the geoelectrical model, $N$ represent the num- ber of layers; $\rho$, the resistivity of the layer; $h$, thickness of the layer; $P$, depth; the abscissa axis represents the opening of electrodes $\mathrm{AB} / 2$; and the ordinate axis represents the apparent resistivity.

Figure 14 shows the resistivity pseudo-section (previously 


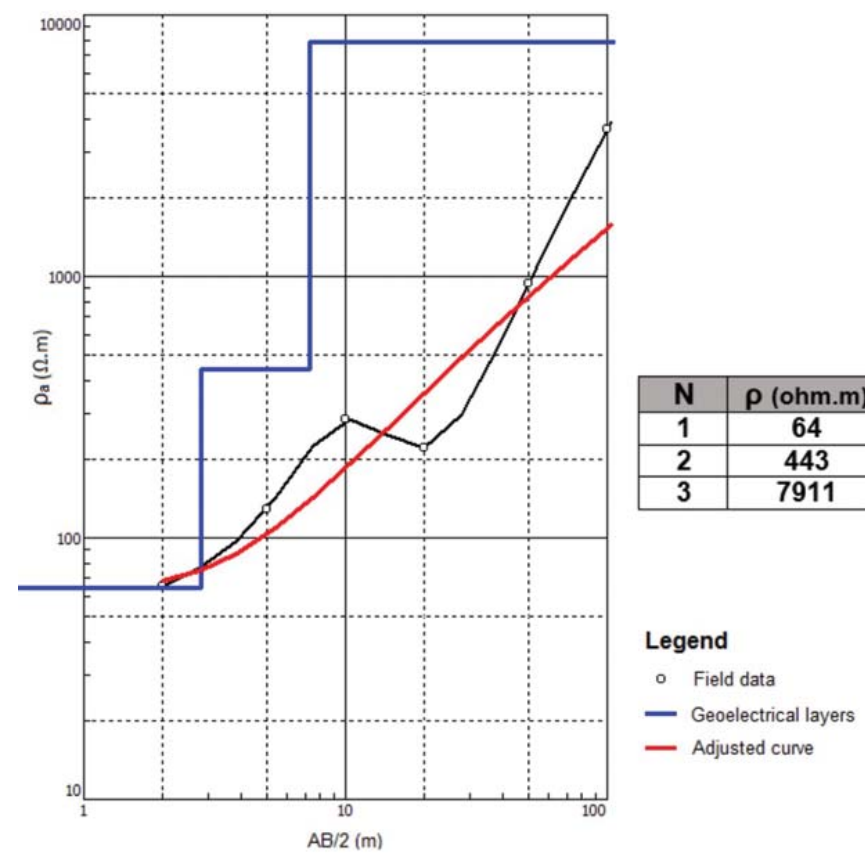

Figure 11 - Apparent resistivity curve of the VES04 and its geoelectrical model. $\mathrm{N}$ represents the number of layers; $\rho$, the resistivity of the layer; $\mathrm{h}$, thickness of the layer; and $\mathrm{P}$, depth.

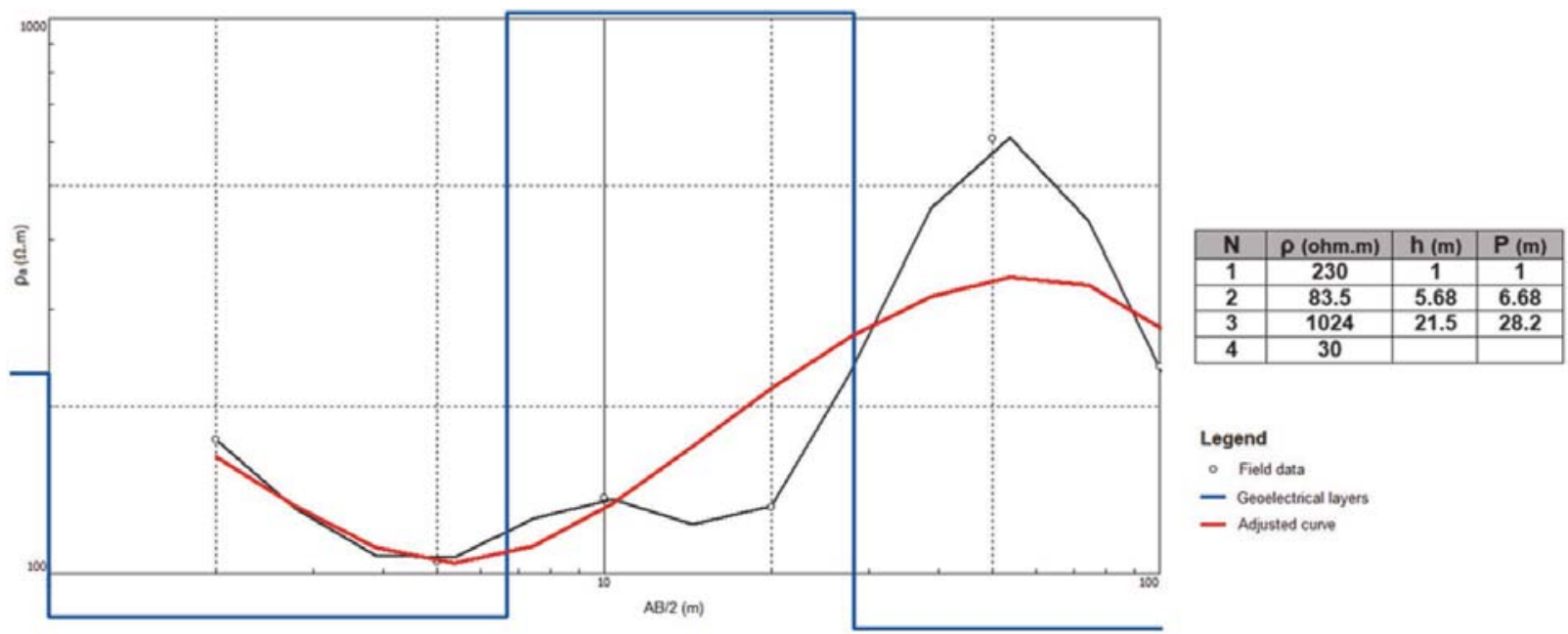

Figure 12 - Apparent resistivity curve of the VES07 and its geoelectrical model. $N$ represents the number of layers; $\rho$, the resistivity of the layer; $h$, thickness of the layer; and P, depth.

the inversion) and Figures 15 and 16 present the results of inversion the real data using the software IPI2Win. Figure 15 shows the result of the inversion of the raw data, with detail of the 10 VES's performed and the resistivity and thickness of each layer. Then, the interpreted geological model is shown in Figure 16.

From the results of the inversion of real data, it sought an interpretation based on geological context of carbonate rocks and synthetic models previously worked. Analyzing the results of the real data, it was possible to infer probable cavities, areas of dissolution, a layer of fractured limestone with conductive material, a sedimentary cover, among other characteristics similar to those observed in synthetic models and in the field, which corroborated the modeled data.

In Figure 15 (resistivity section) a variation in resistivity between $60 \Omega . \mathrm{m}$ and $500 \Omega . \mathrm{m}$ can be observed (green and blue light colors) in the most superficial portion of the data, along the 


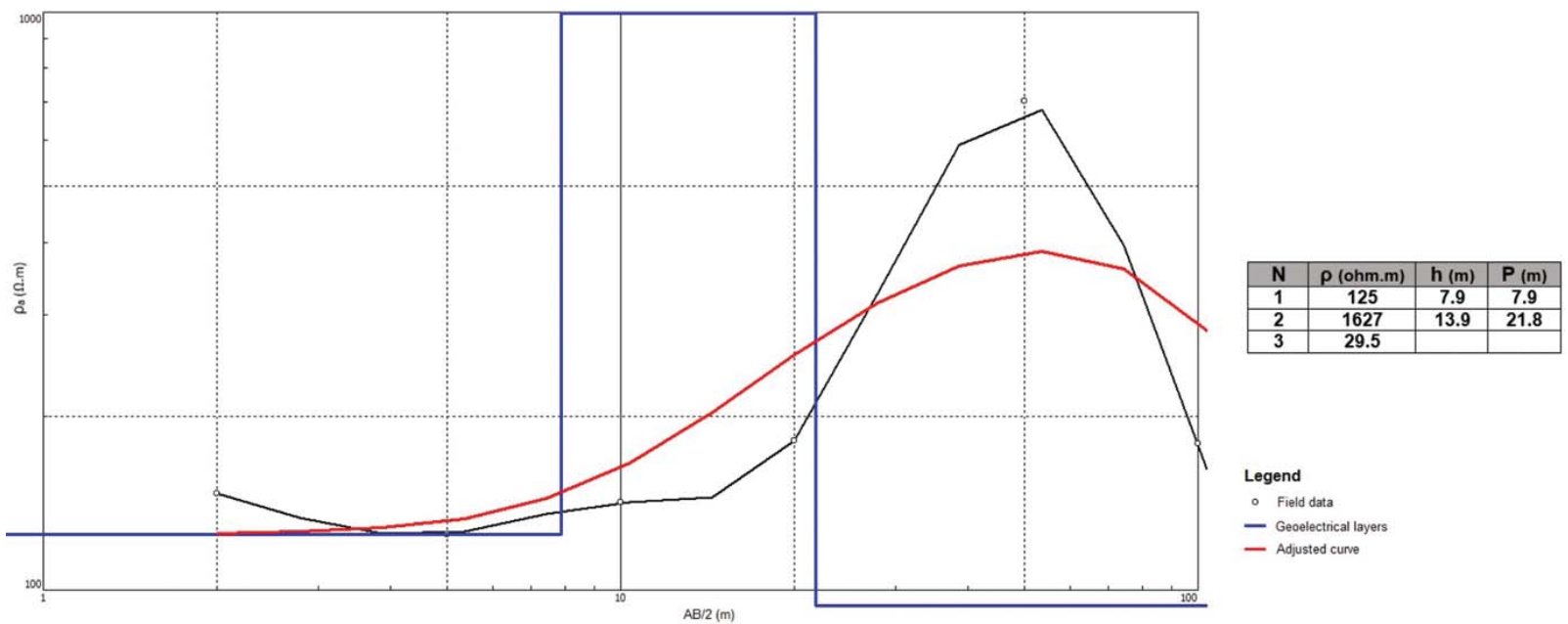

Figure 13 - Apparent resistivity curve of the VES08 and its geoelectrical model. N represents the number of layers; $\rho$, the resistivity of the layer; $h$, thickness of the layer; and P, depth.

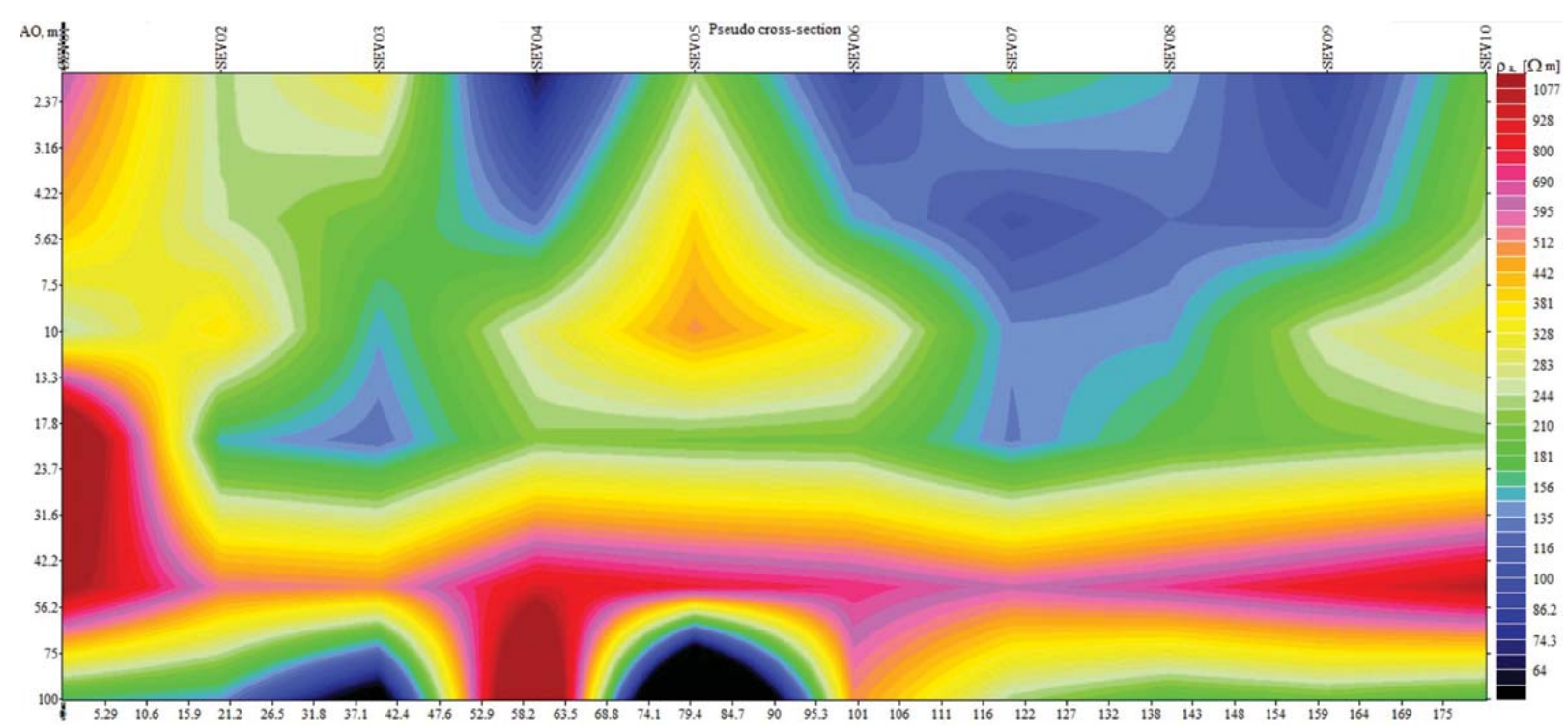

Figure 14 - Resistivity pseudo-section obtained by Schlumberger array.

entire profile, which can be interpreted as a sedimentary cover (see Fig. 16). Under this coverage, there are resistivity values

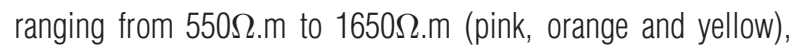
reaching depths of about $50 \mathrm{~m}$ (VES10) and closer to the surface to a depth of less than $5 \mathrm{~m}$ (VES05). Possibly, these values are related to the limestone layer.

In the VES'S 01, 02, 03, 05, 07, 08, 09 and 10 (Fig. 15), in the lower portion are highlighted (black and dark blue colors) low resistivity anomalies ranging between $5 \Omega . \mathrm{m}$ and $35 \Omega$.m, which probably are related to the water table, however, depending on the period of data acquisition, could also be interpreted as a fractured limestone with a conductive material, such as some clay. In VESO6, a value of resistivity diverges from the values observed in that region, in less than $30 \mathrm{~m}$ deep. This zone $(243 \Omega . \mathrm{m})$ can be interpreted as a partially weathered limestone with strong influence of the two adjacent low resistivity areas. In VES04, a layer over $40 \mathrm{~m}$ thick, a depth slightly less than $10 \mathrm{~m}$ and featuring a highly resistive anomaly, approximately $8000 \Omega$.m, is highlighted in data. In this case, the anomaly may have two completely different interpretations: a cavity with 


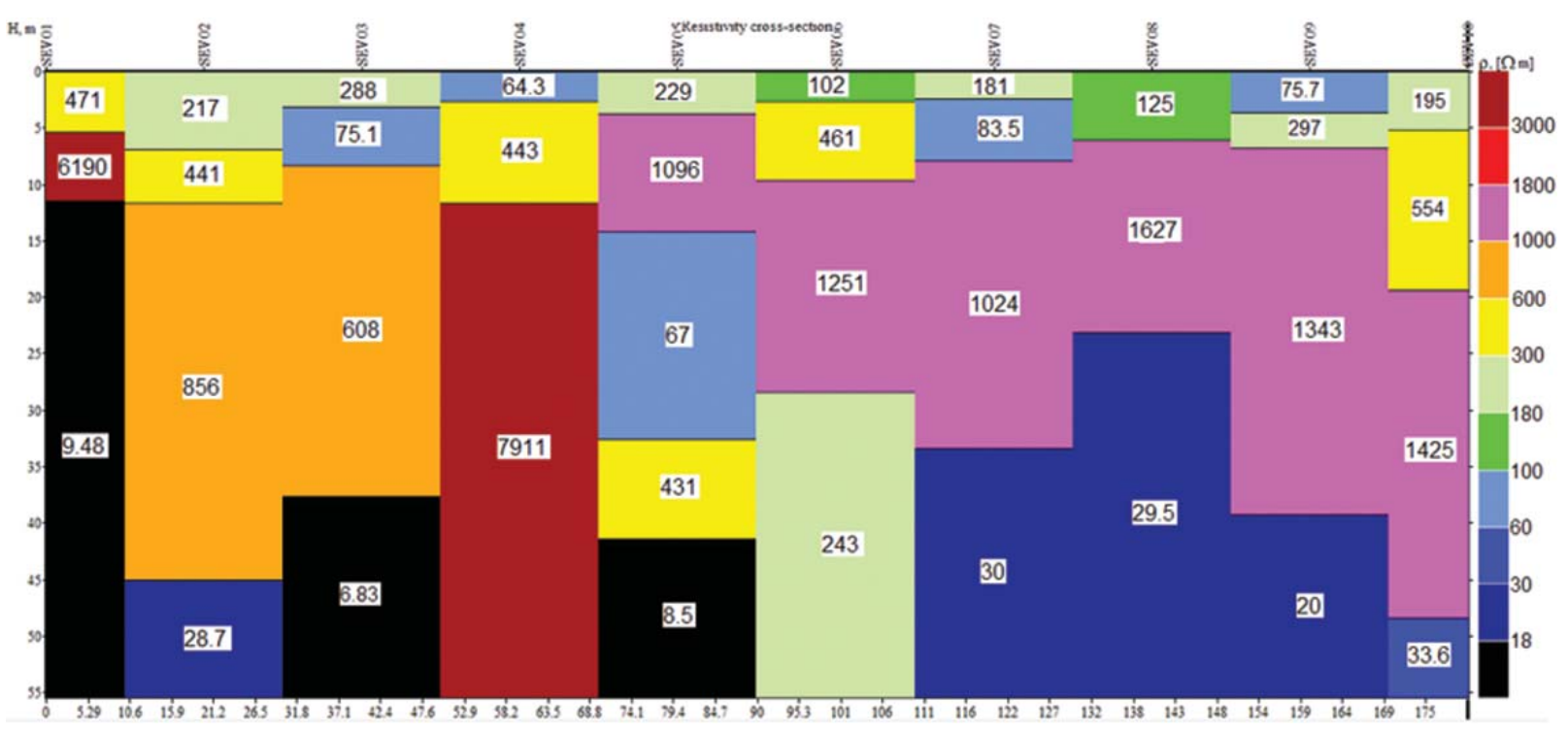

Figure 15 - Resistivity cross-section obtained by Schlumberger array.

air or an extremely competent limestone. This ambiguity could be solved by the calibration of the geophysical data, from its integration with a lithologic log and a well logging, for example. The interpretation of the geological model obtained was based on observations in the field (see Fig. 10), in situ analysis, geophysical data, and information available in the literature, which allowed to infer the most common features in karst environments.

\section{DISCUSSION}

Based on the results obtained after the inversion phase, it was observed that, for the setting of raw data (electrode spacing of $5 \mathrm{~m}$, 16 levels of research and 60 electrodes), each arrangement had advantages and disadvantages, allowing, in some cases, to analyze satisfactorily (in terms of resolution and depth of investigation) the carbonate substrate and their zones of dissolution.

In general, the results revealed that the Dipole-Dipole and Schlumberger arrays showed good vertical resolution (see Figs. 6a, 6b, 7a and 7b), while the Wenner array demonstrated somewhat lower (see Figs. 6c, 7c and 8c). As for the horizontal resolution, the Wenner and Schlumberger arrays were higher than the Dipole-Dipole, featuring good results (see Figs. 8a and $8 \mathrm{c}$ ). Regarding the depth of investigation, the Wenner array reached approximately $40 \mathrm{~m}$ depth, the Schlumberger array approximately $35 \mathrm{~m}$, and the Dipole-Dipole array approached $20 \mathrm{~m}$ deep. However, the Dipole-Dipole presented the greatest amount of imaged points, 792 data points, while 672 data points were imaged by Schlumberger, and 552 data points by the Wenner array.
In the case of the first modeling, the Dipole-Dipole and Schlumberger arrays succeeded in imaging satisfactorily the proposed fractures. However the Dipole-Dipole showed a better result, allowing a clear imaging of the vertical cavity, located approximately $160 \mathrm{~m}$ from the first electrode, with a good resolution both vertically and horizontally (Fig. 6b). The Schlumberger array imaged well the vertical cavity of the model, although with a horizontal resolution less than the Dipole-Dipole array, featuring a little distortion at cavity width (Fig. 6a).

For the model considered more complex (second and third modeling) it was revealed two distinct behaviors in the contours of the resistivity anomalies. In resistive models (Figs. 6 and 7), the inversions showed well-bounded anomalies vertically (with the exception of responses associated with Wenner), and the low resistivity model (Fig. 8), anomalies extremely flatter and well defined, with less emphasized vertical anomalies.

Considering the resistive model proposed in the second modeling (Fig. 7), it is observed a good correlation between the vertical resistivity anomalies (inverted model) and the vertical cavities of the geologic model, especially for the Dipole-Dipole and Schlumberger.

On the other hand, in terms of horizontal resolution, none of the arrangements used allowed the identification of limestone layer located between the two horizontal cavities, with a homogenous behavior between $7.5 \mathrm{~m}$ and $20 \mathrm{~m}$ depth, thereby excluding a layer of $5 \mathrm{~m}$ in thickness. The Schlumberger and Dipole-Dipole arrays were effective at imaging the four vertical cavities, the top of the upper horizontal cavity and the base of the lower horizontal cavity (Figs. 7a and 7b). 


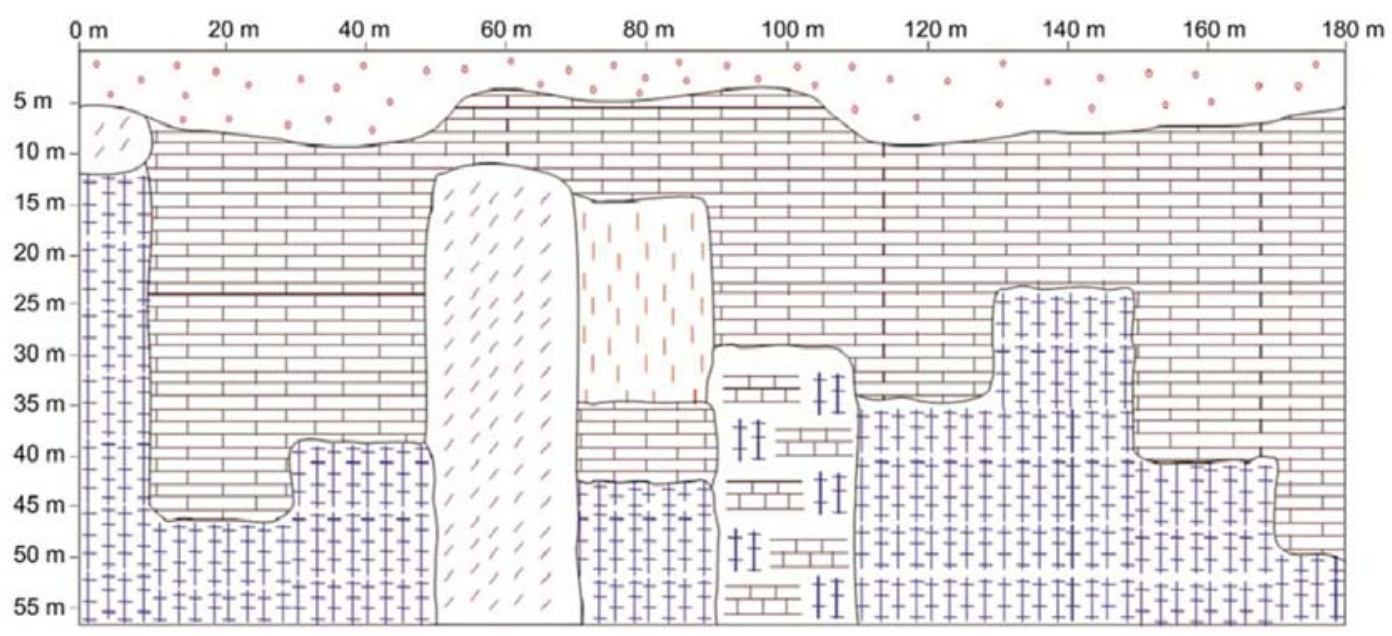

Legend
Sedimentar Cover
III Limestone
†f Cavity with water or clay material
Competent limestone or cavity with air
Low resistivity fractured limestone

Figure 16 - Interpreted geological model obtained by Schlumberger array.

For the proposed modeling in third model (Fig. 8), you may notice a change in the forms of resistivity anomalies, especially in the sections of resistivity associated with Schlumberger and Wenner arrays (Figs. 8a and 8c). Flatter anomalies stood out in the data, highlighting the contact between the saturated and the unsaturated zone and masking the real positioning of the discontinuities filled with water. The vertical cavities air-filled were softly imaged by Schlumberger and Wenner arrays, while the DipoleDipole array they were quite pronounced.

By analyzing real data, in a region with more than $40 \mathrm{~m}$ thick stood out an extremely resistive anomaly (Fig. 16), generating an ambiguity in the interpretation of data. From a geotechnical point of view, this could be considered a suitable location for build any type of edification if such structure was confirmed as a competent limestone. However, if was confirmed the presence of a cavity with air, it could be an extremely dangerous area for the installation of any type of structure with a huge risk of a collapse of the surface.

\section{CONCLUSIONS}

The forward modeling proved to be of fundamental importance for scheduling surveys conducted previously in the field. A qualitative analysis of the results may contribute to the early stage of planning, helping to identify the most appropriate electrodes arrays for different types of structures (simple or complex geological models), besides all parameterization of the acquisition (for example, number and spacing of electrodes).
Regarding results obtained by the inversion, we observed the elimination of certain distortions in the pseudo-sections of apparent resistivity, especially those related to Dipole-Dipole and Wenner, showing the importance of the inversion phase towards a geoelectrical survey. Comparatively, Schlumberger and Dipole-Dipole arrays presented great similarity in terms of horizontal resolution, providing the most satisfactory results in relation to the imaging of the fractures and cavities proposed in the modeling.

In the simplest model, the Dipole-Dipole array imaged more accurately the vertical cavity, while Schlumberger showed a good vertical and horizontal resolution on all models, evidencing both the vertical and horizontal cavities, as well as the contact between the saturated and unsaturated zones. Among the more complex models that showed low resistivity anomalies (fractures filled with water), all of the three arrays allowed the visualization of contact between the saturated and unsaturated zones. However, it wasn't possible to enhance the imaging of the vertical cavities, hindering the observation of the real placement of structures.

Analyzing the pseudo-sections and resistivity sections of Schlumberger array, it was possible to concluded that the "raw data" (pseudo-section), in some cases (resistive models - without the presence of water), showed a more clear response than the own inverted geoelectric section with respect to the imaging of vertical cavities.

The results also allowed to concluded that, in accordance with the proposal and modeled geology, the periods in which the 
water table is closer to the surface, would not be the most suitable for the acquisition of geoelectric data, at least if considered the interest in research from deeper levels (few tens of meters). In this particular case, analyzing the same structure, it would present two distinct geoelectric behaviors: one more resistive (shallower portion) without influence caused by groundwater level and another one less resistive (the deepest portion), affected by water table. In such cases, it may be inferred that an area showing lower resitivities (affected by the water level) can mask the geophysical response of saturated water in vertical and horizontal cavities or fractures, interfering in the definition of the actual lateral positioning of discontinuities and affecting the identification of the structure as a whole, for the highest levels of research.

Based on the results reported herein, we conclude that the Dipole-Dipole and Schlumberger arrays were the most suitable for electrical imaging of vertical structures present in karst systems, while the Wenner array could be more suitable for surveys with the purpose of imaging the top of saturated zone (groundwater), for example. Finally, none of the aforementioned arrays, in accordance with the acquisition parameter used, showed enough vertical resolution to prevent the suppression of the limestone top layer situated between the base of first horizontal cavity (upper) and the top of the lower horizontal cavity.

From a geotechnical/environmental perspective, these may be considered significant results for different areas, such as areas of ground water or oil exploration, as well as in civil engineering, since the analysis of the substrate from the electric imaging, and in turn, the definition of danger zones (areas with potential risk evidenced by dissolution in depth) has a direct impact on the operation of a particular area of study. This is due to the fact that the many areas of exploration have a large number of facilities, exemplified by buildings, storage tanks, separation units oil/water, pipe, among others. Seeking to minimize the risk of possible collapse of land, all infrastructure must be located in a stable area from the geotechnical point of view. Considering this, locating structures that may indicate a risk of collapse of the surface is primordial to the safety of facilities and all of those who go around these areas. In this context, the resistivity geophysical method proved to be an important tool in imaging these zones of dissolution, typical of karstic systems.

\section{ACKNOWLEDGEMENTS}

The authors wish to thank the Agência Nacional do Petróleo, Gás Natural e Biocombustíveis (ANP), through the Programa de Formação em Geologia, Geofísica e Informática para o Setor Petróleo e Gás at UFRN (PRH22), for financing this work and to be providing the scholarship to Lucas M.G. Nunes; the Conselho
Nacional de Desenvolvimento Científico e Tecnológico (CNPq, process number 480753/2011-3, bid number 14/2011), for the approval of Carlos C. Nascimento Silva research project, which contributed to the data presented; the Instituto Nacional de Ciência e Tecnologia Geofísica do Petróleo (INCT-GP); thank the Department of Geophysics (DGEF), for all infrastructure available for the project development. Finally, the authors thank the anonymous reviewers of this article.

\section{REFERENCES}

ATEKWANA EA, SAUCK WA \& WERKEMA JR DD. 2000. Investigations of geoelectrical signatures at a hydrocarbon contaminated site. Journal of Applied Geophysics, 44: 167-180.

BOBACHEV AA, MODIN IN \& SHEVNIN VA. 2000. IPI2Win v. 2.1, IPI_RES2, IPI_RES3, User's Guide. Geoscan-M Ltd., Moscow, Russia. $25 \mathrm{pp}$.

CHALIKAKIS K, PLAGNES V, GUERIN R, VALOIS R \& BOSCH FP. 2011. Contribution of geophysical methods to karst-system exploration: an overview. Hydrogeology Journal, 19: 1169-1180. D0I 10.1007/s10040011-0746-X.

CLAERBOUT JF \& MUIR F. 1973. Robust modeling with erratic data. Geophysics, 38(5): 826-844.

DEGROOT-HEDLIN C \& CONSTABLE S. 1990. Occam's inversion to generate smooth, two-dimensional models from magnetotelluric data. Geophysics, 55(12): 1613-1624.

DELGADO-RODRÍGUEZ 0, SHEVNIN V, OCHOA-VALDÉSJ \& RYJOV A. 2006. Geoelectrical characterization of a site with hydrocarbon contamination caused by pipeline leakage. Geofísica Internacional, 45(1): 63-72.

EL-QADY G, HAFEZ M, ABDALLA MA \& USHIJIMA K. 2005. Imaging subsurface cavities using geoelectric tomography and groundpenetrating radar. Journal of Cave and Karst Studies, 67(3): 174-181.

FERNANDES CE. 1984. Fundamentos de Prospecção Geofísica. Ed. Interciência, Rio de Janeiro-RJ, Brazil. 190 pp.

GAUTAM P, PANT SR \& ANDO H. 2000. Mapping of subsurface karst structure with gamma ray and electrical resistivity profiles: a case study from Pokhara valley, central Nepal. Journal of Applied Geophysics, (45): 97-110.

GEOTOMO. 2007. RES2DINV ver. 3.56. Rapid 2-D Resistivity \& IP inversion using the least-squares method. User's Manual, 141 pp.

LOKE MH. 2002. RES2DMOD (v.3.01). Rapid 2D resistivity forward modelling using the finite-difference and finite-element methods. $28 \mathrm{pp}$.

LOKE MH. 2004. Tutorial: 2-D and 3-D electrical imaging surveys. $136 \mathrm{pp}$. 
LOKE MH, CHAMBERS JE, RUCKER DF, KURAS 0 \& WILKINSON PB. 2013. Recent developments in the direct-current geoelectrical imaging method. Journal of Applied Geophysics, 95: 135-156. DOI: 10.1016/j.jappge0.2013.02.017.

ORELLANA E. 1972. Prospeccion Geoelectrica en corriente continua. Madrid: Paraninfo. 523 pp.

SASAKI Y. 1992. Resolution of resistivity tomography inferred from numerical simulation. Geophysical Prospecting, 40: 453-464.

SHEVNIN V, DELGADO-RODRÍGUEZ 0, MOUSATOV A, NAKAMURALABASTIDAE \& MEJÍA-AGUILAR A. 2003. Oil pollution detection using resistivity sounding. Geofísica Internacional, 42(4): 613-622.
SHEVNIN V, DELGADO-RODRÍGUEZ 0, MOUSATOV A, NAKAMURALABASTIDA E \& MEJÍA-AGUILAR A. 2005. Geoelectrical characterization of an oil-contaminated site in Tabasco, Mexico. Geofísica Internacional, 44(3): 251-263.

SILVA AB. 2008. Hidrogeologia de Meios Cársticos. In: FEITOSA FAC \& MANOEL FILHO J. (Eds.). Hidrogeologia: conceitos e aplicações. CPRM, LABHID-UFPE, chapter 3.3, 3rd ed., 153-174.

WARD SH. 1990. Resistivity and Induced Polarization Methods. In: WARD SH (Ed.). Geotechnical and Environmental Geophysics. Volume I: Review and Tutorial. Society of Exploration Geophysicists, 147-189.

Recebido em 11 julho, 2014 / Aceito em 23 maio, 2016 Received on July 11, 2014 / Accepted on May 23, 2016 